\section{Forkhead Box P3 (Foxp3) serum level and Foxp3 Gene-Promoter polymorphisms in Egyptian rheumatoid arthritis patients: A case-control study}

\author{
Enas M lkram¹, Ayman A Allam², Takwa E \\ Meawed $^{2}$, Shimaa M Abd EL-Wahab ${ }^{3}$ and \\ Raghdaa A Ramadan ${ }^{2}$
}

\footnotetext{
${ }^{1}$ Microbiology \& Immunology Department, Al-Ahrar Teaching Hospital, Zagazig, Egypt.

${ }^{2}$ Medical Microbiology \& Immunology Department, Faculty of Medicine, Zagazig University, Zagazig, Egypt.

${ }^{3}$ Rheumatology \& Rehabilitation Department, Zagazig University Hospitals, Zagazig, Egypt.
}

The Egyptian Journal of Immunology Volume 28 (2), 2021: 53-64. www.Ejimmunology.org
Corresponding author: Enas Ikram, Department of Medical Microbiology \& Immunology, Al-Ahrar Teaching Hospital, Zagazig, Egypt. Email: dr.enas_ikram@hotmail.com.

\begin{abstract}
Regulatory $\mathrm{T}$ (Treg) cells are the chief player in induction of autotolerance and the transcription factor, Forkhead Box P3 (Foxp3), is the master regulator of their development and function. Polymorphisms in Foxp3 locus affect Foxp3 expression and can influence Treg cell function. This study aimed to determine the frequency of $-3279 \mathrm{C} / \mathrm{A}$ and $-924 \mathrm{~A} / \mathrm{G}$ polymorphisms in the promoter region of the Foxp3 gene in Egyptian rheumatoid arthritis (RA) patients in comparison to apparently healthy controls, to test their association with Foxp3 serum levels as well as with patients' clinical and laboratory features. Also, to evaluate Foxp3 serum level as a putative measure of Foxp3+ Treg cells-mediated immune regulation and disease activity. A total of 136 subjects (68 RA patients and 68 controls) were studied for determining the frequency of both $-3279 \mathrm{C} / \mathrm{A}$ and $-924 \mathrm{~A} / \mathrm{G}$ polymorphisms in the Foxp3 promoter region by PCR-RFLP and measuring their Foxp3 protein serum levels by ELISA. Our results indicated that; -3279 Foxp3 CA and AA genotypes were significantly higher in patients than controls $(\mathrm{OR}(95 \% \mathrm{Cl})=2.86(1.31-6.26)$ and $2.79(1.11-7.07), P=0.008$ and $p=$ 0.03 , respectively). Similarly, -924 AG genotype was significantly higher in patients than controls (OR $(95 \% \mathrm{Cl})=2.92(1.35-6.34) ; P=0.006)$. A significantly higher risk of RA was associated with the Foxp3 polymorphic variants -3279 A and -924 G. There was a statistically significant elevation in Foxp3 serum levels among patients, which was positively correlated to disease activity score and disease grade. In conclusion, Foxp3 polymorphisms influenced the risk of developing RA, but did not influence disease severity or activity. Serum level of Foxp3 is not a reliable indicator of Treg-mediated immune regulation in RA patients.
\end{abstract}

Keywords: Treg, Foxp3, RA

Date received: 23 January 2021; accepted: 22 April 2021 


\section{Introduction}

Rheumatoid Arthritis (RA) is a typical common chronic inflammatory autoimmune disease characterized by joint, bone and cartilage destruction and $T$ cell infiltration of the synovium. RA occupies the forty-second place among diseases highly attributed to global disability, with a two-fold higher morbidity among women compared to men. ${ }^{1}$ It is a disease of multifactorial origin; the pathogenesis of which represents a contribution of genetic factors, epigenetic dysregulation in addition to hormonal and environmental influences. The genetic component involves the combined effect of multiple gene variants, not just mere mutations of a specific gene. Although certain HLA-DR alleles play a significant role in genetically determined susceptibility to RA, they are not sufficient for disease induction. ${ }^{2}$

Foxp3+ regulatory $T$ (Treg) cells are the chief player in induction of autotolerance and immune homeostasis and Foxp3 is their lineagedetermining transcription factor and the master regulator of their development and function. Foxp3 gene is located on chromosome Xp11.23 which is an autoimmune diseases susceptibility locus. Consequently, it has been nominated as a candidate gene in pathogenesis of RA. ${ }^{3.4}$

Different mutations in Foxp3 gene have been described; mutations involving Foxp3 functional domains markedly alter Foxp3 nuclear transport, DNA binding, complex formation with other transcription factors and ultimately its transcriptional activator and repressor functions that result in the heterogeneous biological abnormalities of "Immunodysregulation Polyendocrinopathy Enteropathy X-linked (IPEX)" syndrome. On the other side, polymorphisms in Foxp3 promoter region, mostly affect Foxp3 expression level and consequently alter Treg cell number and function as reported in chronic inflammatory conditions as RA, systemic lupus erythematosus, psoriasis, autoimmune thyroiditis and allergic rhinitis. ${ }^{3,5-10}$

Five functionally relevant single-nucleotide polymorphisms (SNPs) have been described in the Foxp3 promoter region; of which, the significance of $-3279 \mathrm{C} / \mathrm{A}$ and $-924 \mathrm{~A} / \mathrm{G}$ in immune dysregulation have been appreciated in multiple studies. ${ }^{11-15}$ The - 3279C/A and 924A/G polymorphisms alters the Foxp3 transcription by abrogating E47, c-Myb and GATA3 transcription factors attachment to their binding sites respectively, and subsequent autoimmune disease development. ${ }^{6,12}$

Currently, it became certain that ethnicity greatly influences polymorphisms in different genes implicated in the pathogenesis of several immune diseases including RA. Consequently, the aim of this study was to determine the frequency of 2 single nucleotide polymorphisms in the promoter region of the Foxp3 gene; 3279C/A (rs3761548) and -924A/G (rs2232365) in Egyptian RA patients in comparison to apparently healthy controls, to test their association with Foxp3 serum levels as well as with patients' clinical and laboratory features. Also, to evaluate serum Foxp3 protein level as a putative measure of Foxp3+ Treg cells-mediated immune regulation and disease activity.

\section{Subjects and Methods}

\section{Subjects and Study design}

This case control study was conducted in the Medical Microbiology and Immunology Department, Faculty of Medicine, Zagazig University during the period from December 2018 to October 2019. It included 68 Rheumatoid arthritis patients ( 62 females and 6 males) attending the outpatient clinic of the Rheumatology and Rehabilitation Department, Zagazig University Hospitals. Patients fulfilled $\geq$ 4 of criteria of the American College of Rheumatology (ACR 1987). ${ }^{16}$

Sixty-eight apparently healthy subjects (60 females and 8 males) with no evidence or history of immunological disorder were included as the control group. The study protocol was reviewed and approved by the IRB of the Faculty of Medicine, Zagazig University (approval number 3717, June 2017). An informed consent was obtained from all participants before enrolment.

Patients were subjected to full clinical examination and laboratory data relevant to their medical condition including; C-reactive protein (CRP), rheumatoid factor (RF), erythrocyte sedimentation rate (ESR) and anticyclic citrullinated peptide antibodies (ACCP) were taken from their medical records. 


\section{Sample collection}

Blood samples $(3 \mathrm{ml})$ were collected from all study subjects, and aliquoted in plain tubes for serum separation (for detection of Foxp3 level) and in EDTA tubes (for DNA extraction). Sera and anticoagulated blood tubes were stored at $20^{\circ} \mathrm{C}$ until examined.

\section{DNA extraction}

EDTA anticoagulated blood samples were subjected to genomic DNA extraction using Gene JET Whole Blood Genomic DNA Purification Mini Kit (Thermo SCIENTIFIC, China), according to the manufacturer's instructions.

Genotyping by Polymerase Chain ReactionRestriction Fragment Length Polymorphism (PCR-RFLP)

-Amplification of promoter segments containing the polymorphisms

This was performed in a $25-\mu l$ PCR reaction containing: $12.5 \mu \mathrm{l}$ of (2X) PCR Master Mix (Thermo SCIENTIFIC, china) that contains DNA polymerase (Phire Hot Start II), nucleotides and optimized reaction buffer including $\mathrm{MgCl}_{2}$, two microliters of the extracted genomic DNA and 10 pmol of each primer (Thermo SCIENTIFIC, China) either forward 5'-CTTAACCAGACAGCGT AGAAGG-3' and reverse 5'CATCATCACCACGCTCTGG-3', for Foxp3 -3279 $C / A$ polymorphism detection, or forward $5^{\prime}$ AGGAGAAGGAGTGGGCATT- $3^{\prime}$ and reverse: $5^{\prime}$ TGTGAGTGGAGGAGCTGAGG-3', for Foxp3 -924 $A / G$ polymorphism detection. Amplifications were performed in a PCR thermal cycler (Biometra, Germany) under the following conditions: initial denaturing at $95^{\circ} \mathrm{C}$ for $5 \mathrm{~min}$, followed by 35 cycles at $95^{\circ} \mathrm{C}$ for $20 \mathrm{~s} ; 55 \mathrm{C}$ for 20s; and $72^{\circ} \mathrm{C}$ for $30 \mathrm{~s}$ with a final extension at $72^{\circ} \mathrm{C}$ for 5 min. $^{17}$

-Restriction enzyme digestion of the amplified segments and genotype characterization

Foxp3 -3279 C/A polymorphism: Ten microliters of the 399 base pairs (bp) PCR product were digested with $1 \mu$ l of the restriction enzyme Pstl (Thermo SCIENTIFIC, China) for $30 \mathrm{~min}$ at $37^{\circ} \mathrm{C}$, then separated on ethidium bromide-stained agarose gel $(2.5 \%)$. Pstl digestion yielded a 399 bp product for the polymorphic allele $A$ (i.e. undigested), and 188 and 211 bp products for the digested wild type allele (C). (Figure 1)

-Foxp3 -924 A/G polymorphism

Ten microliters of 249 bp PCR product were digested with $1 \mu$ l of the restriction enzyme BsmBI (Thermo SCIENTIFIC, China) for $15 \mathrm{~min}$ at $37^{\circ} \mathrm{C}$, then separated on ethidium bromidestained agarose gel (3\%). BsmBI digestion yielded a $249 \mathrm{bp}$ for the wild type allele A (i.e. undigested), and 117 and 132 bp products for the digested polymorphic allele G. (Figure 2)

Determination of FOXP3 protein serum levels by quantitative ELISA

Serum levels of Foxp3 protein were determined for patients and control subjects using FOXP3 (Human) ELISA Kit (Biovision, USA) with a detection range of $0.313-20 \mathrm{ng} / \mathrm{ml}$. The assay was performed according to the manufacturer's instructions and results were read on a microplate reader (TECAN, Columbus plus, Australia) at $450 \mathrm{~nm}$ within 20 minutes.

\section{Statistical analysis}

The collected data were computerized and statistically analyzed using SPSS program version 18.0. Qualitative data were represented as frequencies and relative percentages. While quantitative data were expressed as mean \pm SD (Standard deviation). Chi square test was used to calculate differences between qualitative variables. Independent $\mathrm{T}$ test was used to calculate differences between quantitative variables in 2 groups in normally distributed data while Mann Whitney $U$ test was used to calculate differences between quantitative variables in 2 groups in non-normally distributed data. Kruskal Wallis test was used to calculate differences between quantitative variables in more than 2 groups in non-normally distributed data. Spearman's correlation coefficient was used to calculate correlation between quantitative variables. $P$ value of $<0.05$ indicates significant results. 


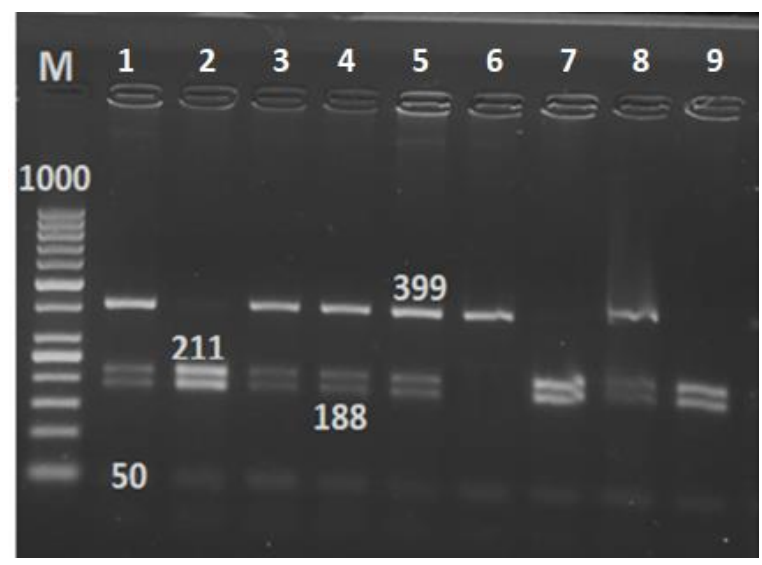

Figure 1. Agarose gel electrophoresis for detection of -3279 C/A Foxp3 polymorphism. A single band of 339 bps indicates AA genotype (lane 6), two bands at 188 and $211 \mathrm{bps}$ indicates CC genotype (lanes 2,7,9) and 3 bands of 399, 211 and 188bps indicate CA genotype (lanes 1,3,4,5,8); (M): molecular weight marker $(50,100,150,200,250,300,400,500$, $600,700,800,900$ and $1000 \mathrm{bps})$.

\section{Results}

\section{Characteristics of the study population}

The studied population mean ages and range were 45.2, 24 - 60 years and 43.8, 25 - 62 years, for patients and control subjects, respectively. Clinical and laboratory data of

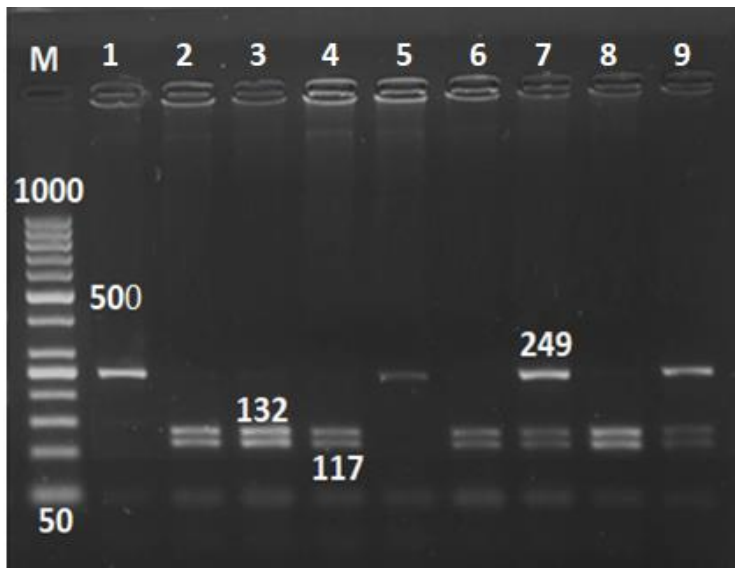

Figure 2. Agarose gel electrophoresis for detection of $-924 A / G$ Foxp3 polymorphism. A single band of 249 bps indicates AA genotype (lanes 1,5), two bands of 117 and 132 bps indicates GG genotype (lanes 2,3,4,6,8) and 3 bands of 249, 117 and 132 bps indicate AG genotype (lanes 7,9). (M) is the molecular weight marker $(50,100,150,200,250$, $300,400,500,600,700,800,900$ and $1000 \mathrm{bps})$.

patients showed that all of them had an active disease as indicated by Disease Activity Score for 28 joints (DAS28) of more than 5.1 (range=5.8-6.4, mean=6.1), ESR was elevated in all patients and CRP was positive in $60 \%$. (Table 1).

Table 1. Clinical and laboratory features of patients

\begin{tabular}{|c|c|c|}
\hline Variable & \multicolumn{2}{|c|}{ Group I (n=68) } \\
\hline \multicolumn{3}{|l|}{ Duration (years) } \\
\hline Mean \pm SD & \multicolumn{2}{|c|}{$4.83 \pm 4.74$} \\
\hline Median(Range) & \multicolumn{2}{|c|}{$3(0.83-20)$} \\
\hline \multicolumn{3}{|c|}{ Age of onset (years) } \\
\hline Mean \pm SD & \multicolumn{2}{|c|}{$40.34 \pm 7.91$} \\
\hline Median(Range) & \multicolumn{2}{|c|}{$43(21-57)$} \\
\hline \multicolumn{3}{|c|}{ Number of swelling joints } \\
\hline Mean \pm SD & \multirow{2}{*}{\multicolumn{2}{|c|}{$\begin{array}{c}5.38 \pm 2.91 \\
5(0-14)\end{array}$}} \\
\hline Median(Range) & & \\
\hline \multicolumn{3}{|c|}{ Number of tender joints } \\
\hline Mean \pm SD & \multicolumn{2}{|c|}{$17.26 \pm 9.51$} \\
\hline Median(Range) & \multicolumn{2}{|c|}{$20(2-28)$} \\
\hline \multicolumn{3}{|l|}{ DAS28 } \\
\hline Mean \pm SD & \multicolumn{2}{|c|}{$6.12 \pm 0.18$} \\
\hline Range & \multicolumn{2}{|c|}{$5.8-6.4$} \\
\hline \multicolumn{3}{|l|}{ Morning stiffness } \\
\hline $30 \mathrm{~min}$ & 6 & 8.8 \\
\hline $1 \mathrm{~h}$ & 60 & 88.2 \\
\hline $2 \mathrm{~h}$ & 2 & 2.9 \\
\hline
\end{tabular}


Table 1. (Continued)

\begin{tabular}{|c|c|c|}
\hline Variable & Group I ( $n=$ & \\
\hline Dry mouth & & \\
\hline Yes & 52 & 76.5 \\
\hline No & 16 & 23.5 \\
\hline Dry eye & & \\
\hline Yes & 59 & 86.8 \\
\hline No & 9 & 13.2 \\
\hline Grade: & & \\
\hline I & 48 & 70.6 \\
\hline II & 12 & 17.6 \\
\hline III & 8 & 11.8 \\
\hline ESR & & \\
\hline Normal & 0 & 0 \\
\hline High & 68 & 100 \\
\hline CRP & & \\
\hline -ve & 27 & 39.7 \\
\hline$+v e$ & 41 & 60.3 \\
\hline $\mathrm{RF}$ & & \\
\hline -ve & 16 & 23.5 \\
\hline +ve & 52 & 76.5 \\
\hline Anti-CCP & & \\
\hline -ve & 44 & 64.7 \\
\hline +ve & 24 & 35.3 \\
\hline
\end{tabular}

Abbreviations: DAS28: Disease Activity Score for 28 joints; CRP: C-reactive protein; ESR: erythrocyte sedimentation rate; RF: rheumatoid factor (> 34IU / ml); anti-CCP: anticyclic citrullinated peptide antibodies (> $17 \mathrm{U} / \mathrm{ml}$ ), -ve: negative and +ve: positive.

\section{Foxp3 serum levels}

Foxp3 serum levels were significantly elevated among RA group compared to the control group (mean $\pm \mathrm{SD}=5.52 \pm 3.31$ and $4.03 \pm 1.19$, respectively, $P=0.01$ ) (Figure 3 ).

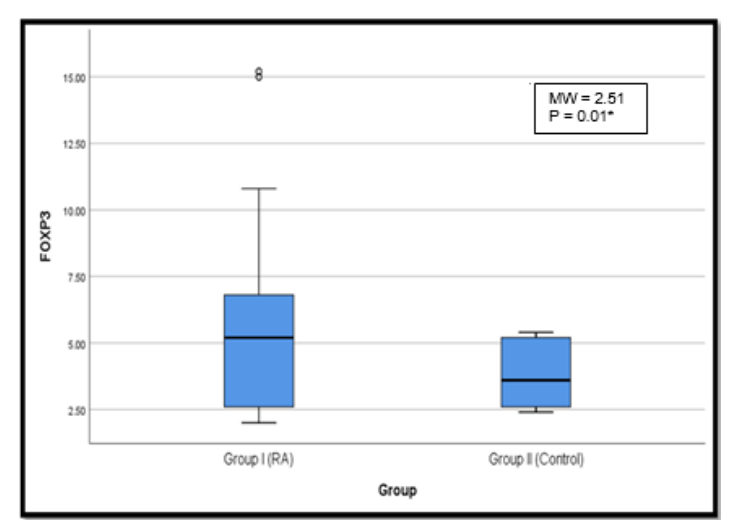

Figure 3. Foxp3 serum level in the studied groups. $\mathrm{MW}=$ Mann Whitney $\mathrm{U}$ test $*$ significant
Foxp3 serum level was significantly, directly correlated to disease activity as presented by DAS28 score and diseases grade (Table 2).

Also, it was significantly positively correlated to both disease duration and number of swelling joints (Table 2).

There was a statistically significant increase in Foxp3 levels among cases who tested positive for CRP, RF and ACCP (Table 3).

\section{Foxp 3 promotor polymorphisms}

Foxp3 -3279 C/A polymorphism: The analysis of -2379 C/A Foxp3 gene polymorphism showed significant differences in distribution between cases and controls under different models of inheritance; RA patients showed a significantly higher frequency of CA and AA genotypes than the control subjects under the codominant model (i.e., both alleles are expressed) $(P=0.008$ and 0.03 , respectively).

Similarly, a significant association was observed with CA and AA genotypes under the 
dominant model [OR 2.84; $\mathrm{Cl}$ (1.40-5.72); $P=$ 0.003]. Under the over dominant model (i.e., heterozygote advantage; heterozygous individuals have a higher fitness than homozygous ones), CA genotype frequency was significantly higher in patients with RA compared to the control subjects $(45.2 \%$ vs $28.3 \%$, respectively $P=0.001$ ).

Also, there was a statistically significant increase in the frequency of $A$ allele $(O R=2.06$, $P=0.001$ ) among RA group compared to the control group (Table 4).
Foxp3 -924 A/G polymorphism: The analysis of 924 A/G Foxp3 gene polymorphism revealed statistically significant increase in frequency of $A G$ genotype and $G$ allele $(O R=1.65)$ among patients compared to the control group. Under the codominant and the over dominant models, AG genotype frequency was significantly higher in patients [OR 2.92; $\mathrm{Cl}(1.35-6.34) ; P=0.006$ ] and [OR 2.4; Cl (1.19-4.86); $P=0.01]$, respectively. A significant association was also observed with $A G$ and $G G$ genotypes under the dominant model, [OR 2.87; $\mathrm{Cl}$ (1.34-6.12); $P$, 0.006] (Table 5).

Table 2. Correlation of serum FOXP3 level with age and clinical data of RA patients

\begin{tabular}{lcc} 
Variable & \multicolumn{2}{c}{$\begin{array}{c}\text { Foxp3 Group I (RA) } \\
(n=68)\end{array}$} \\
\hline Age & $r$ & NS value \\
\hline Duration & 0.08 & 0.02 \\
\hline Age of onset & 0.24 & NS \\
\hline Number of swelling joints & 0.10 & 0.03 \\
\hline Number of tender joints & 0.21 & NS \\
\hline DAS28 & 0.15 & $<0.001$ \\
\hline Morning stiffness & 0.50 & NS \\
\hline Grade & 0.06 & $<0.001$ \\
\hline
\end{tabular}

DAS28: Disease Activity Score for 28 joints. $r$ : Spearman correlation coefficient test. *: $P>0.05$ is not significant (NS).

Table 3. Relation between Foxp3 serum level and laboratory findings among RA group

\begin{tabular}{|c|c|c|c|c|c|c|}
\hline \multirow{2}{*}{ Variable } & & \multirow{2}{*}{ No } & \multicolumn{2}{|c|}{ group I (RA) Foxp3 } & \multirow{2}{*}{$\mathrm{MW}$} & \multirow{2}{*}{${ }^{*} P$ value } \\
\hline & & & Mean $\pm S D$ & Median & & \\
\hline \multirow{2}{*}{ CRP: } & -ve & 27 & $3.6 \pm 1.92$ & 2.7 & \multirow{2}{*}{4.07} & \multirow{2}{*}{$<0.001$} \\
\hline & +ve & 41 & $6.78 \pm 3.44$ & 6.8 & & \\
\hline \multirow{2}{*}{ RF: } & -ve & 16 & $4.25 \pm 2.55$ & 3.75 & \multirow{2}{*}{2.03} & \multirow{2}{*}{0.04} \\
\hline & +ve & 52 & $5.72 \pm 3.51$ & 6 & & \\
\hline \multirow{2}{*}{ Anti-CCP: } & -ve & 44 & $3.8 \pm 1.28$ & 5 & \multirow{2}{*}{2.58} & \multirow{2}{*}{0.03} \\
\hline & +ve & 24 & $5.66 \pm 3.39$ & 7 & & \\
\hline \multirow{2}{*}{$\mathrm{Hb}:$} & Normal & 45 & $4.80 \pm 3.65$ & 5 & \multirow{2}{*}{1.87} & \multirow{2}{*}{ NS } \\
\hline & Low & 23 & $5.89 \pm 3.1$ & 6 & & \\
\hline \multirow{2}{*}{ Creatinine } & Normal & 63 & $5.52 \pm 3.16$ & 5.2 & \multirow{2}{*}{1.24} & \multirow{2}{*}{ NS } \\
\hline & High & 5 & $5.51 \pm \pm 3.64$ & 5 & & \\
\hline \multirow{3}{*}{ Platelets: } & Low & 4 & $4.15 \pm 1.31$ & 4 & \multirow{3}{*}{$\begin{array}{l}\mathrm{KW} \\
4.06\end{array}$} & \multirow{3}{*}{ NS } \\
\hline & Normal & 61 & $5.77 \pm 3.38$ & 5.5 & & \\
\hline & High & 3 & $4.53 \pm 1.44$ & 4.5 & & \\
\hline
\end{tabular}

MW: Mann Whitney U test. KW: Kruskal Wallis test. *: $P>0.05$ is not significant (NS), -ve: negative and +ve: positive. 
Table 4. Foxp3 3279 C/A genotype frequency in female subjects and allele frequency among all subjects in the studied groups

\begin{tabular}{|c|c|c|c|c|c|c|c|c|}
\hline \multirow[t]{2}{*}{ Variable } & & \multicolumn{2}{|c|}{$\begin{array}{c}\text { Group I } \\
\text { (RA) } \\
\text { Females }(n=62)\end{array}$} & \multicolumn{2}{|c|}{$\begin{array}{c}\text { Group II } \\
\text { (Control) } \\
\text { Females }(n=60)\end{array}$} & \multirow[t]{2}{*}{$\chi^{2}$} & \multirow[t]{2}{*}{$\begin{array}{c}{ }^{*} P \\
\text { value }\end{array}$} & \multirow{2}{*}{$\begin{array}{c}\text { OR } \\
(95 \% \mathrm{Cl})\end{array}$} \\
\hline & & No & $\%$ & No & $\%$ & & & \\
\hline \multirow{3}{*}{ Codominant } & $\mathrm{CC}$ & 19 & 30.6 & 33 & 55 & Ref & NS & -- \\
\hline & $\mathrm{CA}$ & 28 & 45.2 & 17 & 28.3 & 7.06 & 0.008 & $2.86(1.31-6.26)$ \\
\hline & $\mathrm{AA}$ & 15 & 24.2 & 10 & 16.7 & 4.87 & 0.03 & $2.79(1.11-7.07)$ \\
\hline \multirow{2}{*}{ Dominant } & $\mathrm{CC}$ & 19 & 30.6 & 33 & 55.9 & Ref & NS & -- \\
\hline & $C A+A A$ & 43 & 69.4 & 27 & 44.1 & 8.65 & 0.003 & $2.84(1.40-5.72)$ \\
\hline \multirow{2}{*}{ Recessive } & $\mathrm{CC}+\mathrm{CA}$ & 47 & 75.8 & 50 & 83.3 & Ref & NS & -- \\
\hline & $\mathrm{AA}$ & 15 & 24.2 & 10 & 16.7 & 1.62 & NS & $1.73(0.74-4.03)$ \\
\hline \multirow{2}{*}{$\begin{array}{l}\text { Over } \\
\text { dominant }\end{array}$} & $\mathrm{CC}+\mathrm{AA}$ & 34 & 54.8 & 43 & 71.7 & Ref & NS & -- \\
\hline & $\mathrm{CA}$ & 28 & 45.2 & 17 & 28.3 & 3.86 & 0.04 & $2.04(1-4.16)$ \\
\hline \multirow[t]{3}{*}{ Allele: } & & $(n=130$ & & $(n=12 \varepsilon$ & & & & \\
\hline & $\mathrm{C}$ & 69 & 52.9 & 91 & 69.9 & \multirow{2}{*}{8.21} & \multirow{2}{*}{0.001} & \multirow{2}{*}{$2.06(1.25-3.39)$} \\
\hline & $A$ & 61 & 47.1 & 37 & 30.1 & & & \\
\hline
\end{tabular}

$\chi^{2}$ : Chai square test. OR: Odds ratio Cl: Confidence interval. *: $P>0.05$ is not significant (NS)

a : The small number of hemizygous males ( 6 patients \& 8 controls) are included in allele frequency analysis.

Table 5. Foxp3 -924 A/G genotype frequency in female subjects and allele frequency among all subjects in the studied groups.

\begin{tabular}{|c|c|c|c|c|c|c|c|c|}
\hline \multirow[t]{2}{*}{ Variable } & & \multicolumn{2}{|c|}{$\begin{array}{c}\text { Group I } \\
\text { (RA) } \\
\text { Females }(n=62)\end{array}$} & \multicolumn{2}{|c|}{$\begin{array}{c}\text { Group II } \\
\text { (Control) } \\
\text { Females }(n=60)\end{array}$} & \multirow[t]{2}{*}{$\chi^{2}$} & \multirow[t]{2}{*}{${ }^{*} P$ value } & \multirow[t]{2}{*}{$\begin{array}{c}\text { OR } \\
(95 \% \mathrm{Cl})\end{array}$} \\
\hline & & No & $\%$ & No & $\%$ & & & \\
\hline \multirow{3}{*}{ Codominant } & AA & 13 & 21 & 23 & 38.3 & Ref & NS & -- \\
\hline & $A G$ & 46 & 74.2 & 35 & 58.3 & 7.62 & 0.006 & $2.92(1.35-6.34)$ \\
\hline & GG & 3 & 4.8 & 2 & 3.3 & 1.82 & NS & $2.49(0.65-9.56)$ \\
\hline \multirow[b]{2}{*}{ Dominant } & AA & 13 & 21 & 23 & 38.3 & Ref & NS & \\
\hline & $A G+G G$ & 49 & 79 & 37 & 61.7 & 7.65 & 0.006 & $\begin{array}{l}2.87(1.34- \\
6.12)\end{array}$ \\
\hline \multirow{2}{*}{ Recessive } & $A A+A G$ & 59 & 95.2 & 58 & 96.7 & Ref & NS & -- \\
\hline & GG & 3 & 4,8 & 2 & 3.3 & 0.10 & NS & $\begin{array}{c}1.22(0.35- \\
4.20)\end{array}$ \\
\hline \multirow{2}{*}{$\begin{array}{l}\text { Over } \\
\text { dominant }\end{array}$} & $A A+G G$ & 16 & 25.8 & 25 & 41.7 & Ref & NS & -- \\
\hline & $A G$ & 46 & 74.2 & 35 & 58,3 & 6.02 & 0.01 & $2.4(1.19-4.86)$ \\
\hline \multirow[t]{3}{*}{ Allele: } & & $(n=130)^{a}$ & & $(n=128)$ & & & & \\
\hline & $A$ & 73 & 56.2 & 88 & 67.6 & \multirow{2}{*}{3.99} & \multirow{2}{*}{0.04} & \multirow{2}{*}{$1.65(1.01-2.70)$} \\
\hline & G & 57 & 43.8 & 40 & 33.4 & & & \\
\hline
\end{tabular}

$\chi^{2}$ : Chai square test. OR: Odds ratio I: Confidence interval *: $P>0.05$ is not significant (NS)

${ }^{a}$ : The small number of hemizygous males ( 6 patients $\& 8$ controls) are included in allele frequency analysis.

Genotype association with clinical and laboratory features, and Foxp3 level

There were no statistically significant differences between -3279 C/A Foxp3 genotypes regarding patients' clinical and laboratory findings except for an increase in disease duration (KW=6.89, $P=0.03)$ and morning stiffness duration $(\chi 2=10.18, P=0.04)$ among patients with genotype AA. There were no differences between -924A/G Foxp3 genotypes regarding clinical or laboratory findings. There was a significant decrease in 
Foxp3 level among patients with-3279 AA among -924 GG genotype (Table 6). genotype $(P=0.03)$, but there was no difference

Table 6. Relation between serum Foxp3 level and -3279 C/A and -924 A/G Foxp3 genotypes among RA group.

\begin{tabular}{|c|c|c|c|c|c|c|}
\hline \multirow{3}{*}{ Variable } & \multicolumn{6}{|c|}{ Group I (RA) } \\
\hline & & \multirow{2}{*}{ No } & \multicolumn{2}{|c|}{ Foxp3 } & \multirow[t]{2}{*}{ KW } & \multirow{2}{*}{${ }^{*} P$ value } \\
\hline & & & Mean \pm SD & Median & & \\
\hline \multirow{3}{*}{$-3279 \mathrm{C} / \mathrm{A}$} & CC & 22 & $7.18 \pm 3.81$ & 7 & \multirow{3}{*}{7.09} & \multirow{3}{*}{0.03} \\
\hline & $A C$ & 28 & $5.51 \pm 3.83$ & 5 & & \\
\hline & AA & 18 & $4.24 \pm 2.22$ & 3.75 & & \\
\hline \multirow{3}{*}{-924 A/G } & $\mathrm{AA}$ & 14 & $5.49 \pm 3.42$ & 5 & \multirow{3}{*}{0.46} & \multirow{3}{*}{ NS } \\
\hline & AG & 46 & $6.25 \pm 4.13$ & 6 & & \\
\hline & GG & 8 & $4.79 \pm 2.23$ & 4.5 & & \\
\hline
\end{tabular}

KW: Kruskal Wallis test $\quad *$ : $P>0.05$ is not significant (NS) SD: standard deviation.

\section{Discussion}

Sixty-eight RA patients were included in our study. Unsurprisingly, the highest percentage of our patients were females (91.2\%). Sex bias in autoimmune diseases is attributed to $X$ chromosome-linked immune related genes, their differential expression in both sexes (i.e. sexual dimorphism) and sex-specific epigenetic regulation including the influence of sex hormones. ${ }^{18}$

The mean duration of RA disease was 4.8 years. All patients had an active disease as indicated by a mean DAS28 score of 6.1 (i.e., more than 5.1) and elevated ESR. Positive CRP, rheumatoid factor and anti-CCP were detected in $60 \%, 76 \%$ and $35 \%$ of the patients, respectively; more or less similar results were detected in other studies; Alzifzaf et al. ${ }^{19}$ and Khalil et al. in Egypt ${ }^{2}$ and Hashemi et al. in Iran. ${ }^{3}$

Foxp3 expression is subjected to two main types of regulation, transcriptional and posttranslational, both of which are responsive to positive and negative regulation by factors in the tissue environment, including cytokines, metabolic mediators and inflammatory factors. ${ }^{21}$ In this perspective, serum level of Foxp3 was postulated to be a reflection of the overall expression process as well as the activity state of Treg cells that takes part in the inflammation rather than a mere reflection of the individual genotype.

In the present study, the mean Foxp3 serum level was significantly higher in patients than control subjects, this was in accordance with findings of a study by Paradowska-Gorycka et al. who reported an elevated serum Foxp3 more in patients than control group $(51 \%$ vs $18 \%$, respectively). ${ }^{17}$ Higher and lower mean Foxp3 levels were reported by Alzifzaf et al. ${ }^{19}$ and Gaafar et $\mathrm{al}^{22}(16.9$ and $1.01 \mathrm{ng} / \mathrm{ml}$ in patients with rheumatoid arthritis vs 26.4 and 1.72 $\mathrm{ng} / \mathrm{ml}$ in control subjects, respectively).

High Foxp3 serum levels in patients compared to controls were explained as attempts of immune system to tame the ongoing inflammation; justified by the observation that elevated Foxp3 serum levels were associated with reduced disease activity in some studies. ${ }^{17}$ Nevertheless, elevated Foxp3 serum level in our study was associated with higher disease activity and elevated inflammatory and autoimmune markers.

Treg cell lineage and functional stability depends on the efficient expression of Foxp3 and several mechanisms act to ensure this; $T$ cell receptor signaling, cytokine signaling (IL2 via STAT5 \& TGFB via SMAD 2,3,4) and methylation pattern of the Treg cell specific demethylated region (TSDR) that determines efficacy of transcription factors binding. 2 However, Treg cells, like other immune cells exhibit some degree of plasticity that allows them to adapt to the changing environmental cues. In this context, Foxp3+ Treg can acquire some features of the immune cells they control, which is beneficial for the immune response, but in some autoimmune conditions dysfunctional plasticity of Treg cells is observed with acquisition of a helper function, secretion of pro-inflammatory cytokines and loss of suppressive function, but maintaining Foxp3 
expression. They are thus termed "Helper T celllike Treg cells". Here they fail to maintain peripheral tolerance but mediate immunopathology. ${ }^{21}$

Supporting this idea, in case of rheumatoid arthritis, IL17 secreting Foxp3+ Treg cells ( $T_{H} 17-$ like Tregs) were detected in the synovial fluid samples of patients with active RA. Moreover, in a collagen-induced arthritis mouse model, the conversion of Foxp3+ Treg cells into $T_{H} 17$ cells mediated by IL- 6 and IL- $1 \beta$ had an important role in the pathogenesis of autoimmune arthritis. ${ }^{23,24,25}$ Meanwhile, Studies had proved that Foxp3 expression is not an exclusive character of Treg cells and promiscuous Foxp3 expression occurs transiently in human conventional T cells (Tcons) during initial rounds of activation-induced proliferation. ${ }^{26}$

In addition to the above-mentioned facts that would explain the presence of an active disease despite elevated Foxp3 level, it has been reported that even with normal Treg cell function, the susceptibility of certain effector $T$ cell (Teff) types and states to the suppressive action of Treg cells may differ; ${ }^{27}$ Teff cells can overcome the inhibitory effect of Treg cells in autoimmune diseases. ${ }^{28}$ Therefore, Treg cells alone may not be able to control robust $T$ cell and $B$ cell activation. ${ }^{29,} 30$ Consequently, Treg/ $/ T_{H} 17$ cell balance was proposed as a new paradigm for autoimmunity rather than the sole Treg state. ${ }^{31,32}$

The present study revealed a significant increase in the frequency of $A C$ and $A A$ genotypes, and $A$ allele among RA group compared to the control group. This was consistent with the results of studies on Iranian and Polish RA patients ${ }^{3,17}$ as well as on Turkish osteoarthritis (OA) patients, ${ }^{13}$ where Foxp3 $3279 A$ allele was associated with a higher risk of disease than the wild type $C$ allele.

The association of $-3279 \mathrm{C} / \mathrm{A}$ polymorphism with other immune diseases have been reported; Gao et al. (2010) found an increased risk of psoriasis associated with the $A C$ and the combined $A C+A A$ genotypes compared with the wild CC genotype in a Han Chinese population. ${ }^{8}$ This polymorphism was also associated with allergic rhinitis and unexplained recurrent spontaneous abortion (URSA) in the same population. ${ }^{14,}{ }^{15}$ The -3279 C/A polymorphism in the Foxp3 gene was also associated with the development and recalcitrant nature of Graves' disease ${ }^{9}$ and with a higher risk of systemic lupus erythematosus with lower anti-dsDNA levels in female patients in Taiwan. ${ }^{7}$

Foxp3 -924A/G genotype and allele frequency study showed an increase in frequency of $A G$ genotype and $G$ allele among RA group compared to the control group. Such finding agrees with that of Paradowska-Gorycka et al. ${ }^{17}$ while Cekin et al. ${ }^{13}$ in their study on knee OA detected no association between Foxp3 924A/G polymorphism and disease development. Foxp3 - 924A/G polymorphism was also associated with an increased risk of developing psoriasis. ${ }^{33}$ and vitiligo. ${ }^{34}$

The present study demonstrated a decrease in Foxp3 level among cases with Foxp3 - 3279 AA genotype and with Foxp3 - 924 GG genotype. Similarly, Hashemi et $a l^{3}{ }^{3}$ who investigated Treg cell frequency in PBMC of Foxp3 -3279 genotypes, demonstrated a significant decrease in Treg cell frequency among patients and control subjects with $A A$ genotype compared to the other genotypes of the same group.

Our results showed that the $-3279 \mathrm{~A}$ and $924 \mathrm{G}$ alleles are RA risk alleles in the Egyptian population as they were significantly higher in patients than control subjects. Due to female predominance in our study population, the small number of hemizygous males (possessing a single copy of $X$ chromosome) was included in allele frequency analysis. Females on the other hand, have two copies of $X$ chromosome but normally one of them is randomly inactivated to balance the dosage of $X$ chromosome-linked genes in both sexes, except for $15 \%$ of $X$-linked genes that escape inactivation. Indeed, Foxp3 gene is subjected to inactivation and one of the two Foxp3 alleles undergoes inactivation so that heterozygous females with a Foxp3 mutation have $\sim 50 \%$ of their cells with active mutant allele and $\sim 50 \%$ with active wild-type allele. However, as exceptions of this rule, skewed $X$ chromosome inactivation (nonrandom silencing of the $X$ chromosome) and imprinting expression of $X$ chromosome genes (allelic expression depends on the sex of the parent from whom the allele was inherited) can occur, which should be taken into consideration. ${ }^{35}, 36$ Therefore, studying significant numbers of male 
patients may contribute to a better understanding of the influence of these polymorphisms in the development, severity and progression of the disease.

Our results denied the presence of associations between the studied Foxp3 genotypes with any of the patients' clinical or laboratory findings indicative of disease activity or severity. Controversial results were reported for such associations; Hashemi et al. ${ }^{3}$ reported a more severe disease phenotype with statistically significant increase in disease duration, activity, deformity, anti-CCP and RF in patients with -3279 Foxp3 CA and AA genotypes compared to CC genotype. On the other hand, Paradowska-Gorycka et al. ${ }^{17}$ detected no association between the Foxp3 -3279 C/A or $924 \mathrm{~A} / \mathrm{G}$ variants and disease phenotype concerning disease activity, laboratory variables and extra-articular manifestations among patients with RA. Discrepant results are possibly due to the polyetiologic nature of the disease with involvement of other factors, apart from Foxp3 genotype, in determining disease severity, progression and response to treatment.

In conclusion, the findings of our study indicated that Foxp3 polymorphisms influenced the risk of developing RA, but such polymorphisms did not influence disease severity or activity probably due to involvement of other interacting variables. Although Foxp3 represents a chief marker of Treg cell development and function, Foxp3 serum level is not a reliable indicator of Treg-mediated immune regulation in RA patients. Its exact significance in allergic and autoimmune disorders needs further investigations.

\section{Author Contributions}

RR conceived and designed the study, RR and EI reviewed the relevant literature and formulated the hypothesis. SA performed patient evaluation and participant selection. El performed patient sample and data collection and provision of study material and reagents. RR and El performed the ELISA and genetic molecular laboratory studies. RR and EI participated in statistical analysis and formulation of results. RR drafted the manuscript. $A A$ and $T M$ supervised all steps of the study. All authors reviewed and approved the final manuscript.

\section{Declaration of Conflicting Interests}

The author(s) declared no potential conflicts of interest with respect to the research, authorship, and/or publication of this article.

\section{Funding}

The research received no specific grant from any funding agency in the public, commrecial, or not-forprofit sectors

\section{Ethical approval}

The study protocol was reviewed and approved by the IRB of the Faculty of Medicine, Zagazig University (approval number 3717, June 2017).

\section{Informed consent}

An informed consent was obtained from all participants before enrolment

\section{References}

1. Dargham SR, Zahirovic S, Hammoudeh M, Al Emadi S, Masri BK, Halabi $\mathrm{H}$, Badsha $\mathrm{H}$, Uthman I, Mahfoud ZR, Ashour H, El Haq WG, Bayoumy K, Kapiri M, Saxena R, Plenge RM, Kazkaz L, Arayssi T. Epidemiology and treatment patterns of rheumatoid arthritis in a large cohort of Arab patients [published correction] PLoS One. 2019;14(3): e0214258].

2. Attias M, Al-Aubodah T, Piccirillo CA. Mechanisms of human FoxP3+ Treg cell development and function in health and disease. Clin Exp Immunol. 2019; 197(1):36-51.

3. Hashemi V, Farrokhi AS, Tanomand A, Babaloo Z, Hojjat-Farsangi M, Anvari E, Tahoori M, Ezzeddini R, Hosseini A, Gharibi T, Ghasem Ghalamfarsa G, Jadidi-Niaragh F. Polymorphism of Foxp3 gene affects the frequency of regulatory $T$ cells and disease activity in patients with rheumatoid arthritis in Iranian population. Immunol Lett. 2018; 204:16-22.

4. Togashi Y, Shitar, K, Nishikawa H. Regulatory T cells in cancer immunosuppression: implications for anticancer therapy. Nat Rev Clin Oncol. 2019; $16,356-371$.

5. Oda J, Hirata B, Guembarovski R, Watanable M. Genetic polymorphism in FOXP3 gene: imbalance in regulatory T-cell role and development of human diseases. J Genet. 2013; 92(1):163-171.

6. Pereira L, Gomes S, Ishak R, Vallinoto A. Regulatory T Cell and Forkhead Box Protein 3 as Modulators of Immune Homeostasis. Front Immunol. 2017; 8:605. 
7. Lin YC, Lee JH, Wu AS, Yu HH, Wang LC, Yang YH, Chiang BL. Association of single-nucleotide polymorphisms in FOXP3 gene with systemic lupus erythematosus susceptibility: a casecontrol study. Lupus. 2011; 20(2):137-143.

8. Gao L, Li K, Li F, Li H, Liu L, Wang L, Zhang Z, Gao $\mathrm{T}$, Liu Y. Polymorphisms in the FOXP3 gene in Han Chinese psoriasis patients. J Dermatol Sci. 2010; 57:51-6.

9. Inoue $N$, Watanabe $M$, Morita $M$, Tomizawa $R$, Akamizu T, Tatsumi K, Hidaka Y, Iwatani Y., et al. Association of functional polymorphisms related to the transcriptional level of FOXP3 with prognosis of autoimmune thyroid diseases. Clin Exp Immunol. 2010; 162(3):402-406.

10. Fodor $E$, Garaczi $E$, Polyánka $H$, Koreck A, Kemény L, Széll M. The rs3761548 polymorphism of FOXP3 is a protective genetic factor against allergic rhinitis in the Hungarian female population. Hum Immunol. 2011; 72(10):926-929.

11. Elsohafy MA, Elghzaly AA, Abdelsalam HM, Gaballah MA. Assessment of the Possible Role of FOXP3 Gene (rs3761548) Polymorphism in Psoriasis Vulgaris Susceptibility and Pathogenesis: Egyptian Study. Indian Dermatol Online J. 2019; 10(4):401-405.

12. Xia SL, Ying SJ, Lin QR, Wang XQ, Hong WJ, Lin ZJ, Luo JK. Jiang Y. Association of Ulcerative Colitis with FOXP3 Gene Polymorphisms and Its Colonic Expression in Chinese Patients. Gastroenterol Res Pract. 2019; 2019:4052168.

13. Cekin N, Pinarbasi E, Bildirici AE, Donmez G, Oztemur Z, Bulut O, Arslan S. FOXP3 rs3761548 polymorphism is associated with knee osteoarthritis in a Turkish population. Int J Rheum Dis. 2018; 21(10):1779-1786.

14. Zhang L, Zhang Y, Desrosiers M, Wang C, Zhao Y, Han D. Genetic association study of FOXP3 polymorphisms in allergic rhinitis in a Chinese population. Hum Immunol. 2009; 70:930-934.

15. Wu Z, You Z, Zhang C, Li Z, Su X, Zhang X, Li Y. Association between functional polymorphisms of Foxp3 gene and the occurrence of unexplained recurrent spontaneous abortion in a Chinese Han population. Clin Dev Immunol. 2012; 2012:896458.

16. Arnett FC, Edworthy SM, Bloch DA, McShane DJ, Fries JF, Cooper NS, Healey LA, Kaplan SR, Liang $\mathrm{MH}$, Luthra HS, Medsger TA, Mitchell DM, Neustadt DH, Pinals RS, Schaller JG, Sharp JT, Wilder RL, Hunderet GG. The American Rheumatism Association 1987 revised criteria for the classification of rheumatoid arthritis. Arthritis Rheum. 1988; 31: 315-24.

17. Paradowska-Gorycka A, Jurkowska $M$, FelisGiemza A, Romanowska-Próchnicka K, Manczak M, Maslinski S, Olesinska M. Genetic polymorphisms of Foxp3 in patients with rheumatoid arthritis. J Rheumatol. 2015; 42(2):170-180.

18. Dai R, Ahmed SA. Sexual dimorphism of miRNA expression: a new perspective in understanding the sex bias of autoimmune diseases. Ther Clin Risk Manag. 2014; 10:151-163.

19. AL-Zifzaf DS, El Bakry SA, Mamdouh R, Shawarby L, Abdel Ghaffar A, Amer H, Abd Alim A, Sak Hr, Abdel Rahman R. FoxP3+T regulatory cells in Rheumatoid arthritis and the imbalance of the Treg/TH17 cytokine axis. The Egyptian Rheumatologist. 2015; 37:7-15.

20. Khalil F, Rafat M, Lotfy A, Hemida $M$, Sayed $M$, Attia M. Study of FoxP3+ CD4+ CD25+ in systemic lupus erythematosus and rheumatoid arthritis. The Egyptian journal of internal medicine. 2018; 30(4): 289-299.

21. Dominguez-Villar M, Hafler DA. Regulatory T cells in autoimmune disease. Nat Immunol. 2018; 19(7):665-673.

22. Gaafar T, Farid R, Raafat $H$, Bayoumi F, Gerges B, Rasheed D. The TH17/Treg Imbalance in Rheumatoid Arthritis and Relation to Disease Activity. J Clin Cell Immunol. 2015; 6:6.

23. Voo KS, Wang YH, Santori FR, Boggiano C, Wang YH, Arima K, Bover L, Hanabuchi S, Khalili J, Marinova $E$, Zheng $B$, Littman DR, Liu YJ. Identification of IL-17-producing FOXP3+ regulatory T cells in humans. Proc Natl Acad Sci USA. 2009; 106(12):4793-4798.

24. Kryczek I, Wu K, Zhao E, Wei S, Vatan L, Szeliga W, Huang E, Greenson J, Chang A, Roliński J, Radwan P, Fang J, Wang G, Zou W. IL-17+ regulatory $T$ cells in the microenvironments of chronic inflammation and cancer. J Immunol. 2011; 186(7):4388-4395.

25. Komatsu N, Okamoto K, Sawa S, Nakashima T, Oh-hora M, Kodama T, Tanaka S, Bluestone JA, Takayanagi $H$. Pathogenic conversion of Foxp3+ $T$ cells into TH17 cells in autoimmune arthritis. Nat Med. 2014; 20(1):62-68.

26. Miyao T, Floess $S$, Setoguchi R, Luche $H$, Fehling HJ, Waldmann H, Huehn J, Hori S. Plasticity of Foxp3 (+) T cells reflects promiscuous Foxp3 expression in conventional $T$ cells but not reprogramming of regulatory $T$ cells. Immunity. 2012; 36(2):262-275.

27. Kraczyk B, Remus R, Hardt C.: CD49d Treg cells with high suppressive capacity are remarkably less efficient on activated CD45RA- than on naive CD45RA+ Teff cells. Cell Physiol Biochem. 2014; 34:346-355.

28. Venigalla RK, Tretter $T$, Krienke $S$, Max R, Eckstein V, Blank N, Fiehn C, Ho AD, Lorenz HM. Reduced CD4+, CD25- $T$ cell sensitivity to the suppressive function of CD4+, CD25high, CD127 -/low 
regulatory $\mathrm{T}$ cells in patients with active systemic lupus erythematosus. Arthritis Rheum. 2008; 58(7):2120-2130.

29. Dolff S, Bijl M, Huitema MG, Limburg PC, Kallenberg CG, Abdulahad WH. Disturbed Th1, Th2, Th17 and T (reg) balance in patients with systemic lupus erythematosus. Clin Immunol. 2011; 141(2):197-204.

30. Tao JH, Cheng M, Tang JP, Liu Q, Pan F, Li XP. Foxp3, Regulatory $\mathrm{T}$ Cell, and Autoimmune Diseases. Inflammation. 2017; 40(1):328-339.

31. Eisenstein EM, Williams CB. The $T$ (reg)/Th17 cell balance: a new paradigm for autoimmunity. Pediatr Res. 2009; 65 (5):26-31.

32. Taha $H$, Hozayen W, Okasha A, Ahmed A, Shata M, Abdel Naem E, Maher S. Investigating the Balance between Th17/Treg Cells in Rheumatoid Arthritis and its Association with Disease Activity. J Child Sci. 2019; 9:e75-e83
33. Song $Q$, Shen $Z$, Xing $X$, Yin $R$, Wu $Y Z$, You $Y$, Guo $H$, Chen L, Bai $Y$. An association study of single nucleotide polymorphisms of the FOXP3 intron-1 and the risk of Psoriasis vulgaris. Indian J Biochem Biophys. 2012; 49(1):25-35.

34. Song $P$, Wang XW, Li HX, Li K, Liu L, Wei C, Jian Z, Yi XL, Li Q, Wang G, Li CY, Gao TW. Association between FOXP3 polymorphisms and vitiligo in a Han Chinese population. $\mathrm{Br} J$ Dermatol. 2013; 169(3):571-578.

35. Sun BK, Tsao H. X-chromosome inactivation and skin disease. J Invest Dermatol. 2008; 128(12):2753-2759.

36. Libert C, Dejager L, Pinheiro I. The X chromosome in immune functions: when a chromosome makes the difference. Nat Rev Immunol. 2010; 10(8):594-604. 